Original Article

\title{
The changes of pulmonary function and pulmonary strength according to time of day: a preliminary study
}

\author{
Min-Hyung Rhee, MS, PT ${ }^{1)}$, Laurentius Jongsoon Kim, PhD, $\mathrm{PT}^{2)^{*}}$ \\ 1) Department of Rehabilitation Medicine, Pusan National University Hospital, Republic of Korea \\ 2) Department of Physical Therapy, College of Health Sciences, Catholic University of Pusan: 9 Bugok \\ 3-dong, Geumjung-gu, Busan 609-757, Republic of Korea
}

\begin{abstract}
Abstact. [Purpose] The purpose of this study was to identify changes in pulmonary function and pulmonary strength according to time of day. [Subjects and Methods] The subjects were 20 healthy adults who had no cardiopulmonary-related diseases. Pulmonary function and pulmonary strength tests were performed on the same subjects at 9:00 am, 1:00 pm, and 5:00 pm. The pulmonary function tests included forced vital capacity (FVC), forced expiratory volume in 1 second $\left(\mathrm{FEV}_{1}\right)$, and forced expiratory flow between 25 and $75 \%$ of vital capacity $\left(\mathrm{FEF}_{25-75 \%}\right)$. Pulmonary strength tests assessed maximal inspiratory pressure (MIP) and maximal expiratory pressure (MEP). [Results] FEV1 showed statistically significant differences according to time of day. Other pulmonary function and pulmonary strength tests revealed no statistical differences in diurnal variations. [Conclusion] Our findings indicate that pulmonary function and pulmonary strength tests should be assessed considering the time of day and the morning dip phenomenon.

Key words: Breathing, Time of day, Diurnal variations
\end{abstract}

(This article was submitted May 16, 2014, and was accepted Jun. 27, 2014)

\section{INTRODUCTION}

Increased pollution from rapid industrialization and increases in the smoking rate are gradually focusing public attention on respiratory disorders. Breathing, the major function of the lung, is the process that alternately performs inspiration and expiration with gas exchange that is essential for humans life ${ }^{1)}$. Deteriorating lung function is a major cause of death among South Koreans, and the number of patients with poor lung function is increasing ${ }^{2)}$. Managing lung function can improve dyspnea and enhance quality of life ${ }^{3)}$, consequently public attention to respiratory physiotherapy is increasing. In respiratory physiotherapy, respiratory evaluation is a highly important factor. In particular, the evaluation of pulmonary function is performed to assess the lung's mechanical functions, volume, and capacity ${ }^{4}$. Specifically, peak expiratory flow (PEF), forced vital capacity $(\mathrm{FVC})$, forced expiratory volume in 1 second $\left(\mathrm{FEV}_{1}\right)$, $\mathrm{FEV}_{1} / \mathrm{FVC}$, and forced expiratory flow between 25 and $75 \%$ of vital capacity $\left(\mathrm{FEF}_{25-75 \%}\right)$ are related to the degree of disability and short-term and long-term prognoses in a variety of respiratory diseases and are frequently used as assessment tools ${ }^{5)}$. In addition, maximal inspiratory pressure

*Corresponding author. Laurentius Jongsoon Kim (E-mail: ptjskim@cup.ac.kr)

(C2015 The Society of Physical Therapy Science. Published by IPEC Inc. This is an open-access article distributed under the terms of the Creative Commons Attribution Non-Commercial No Derivatives (by-ncnd) License $<$ http://creativecommons.org/licenses/by-nc-nd/3.0/>.
(MIP) and maximal expiratory pressure (MEP) are performed to evaluate pulmonary strength. These are known to be useful clinical indicators of the natural progress of chronic obstructive pulmonary disease (COPD) patients ${ }^{6}$.

Various human organs, including the lung, exhibit circadian rhythms in which physiological functions are controlled according to a specific cycle. Circadian rhythms appear in growth hormone levels and blood pressure ${ }^{7,8)}$. Recently, postural control has been reported to be related to diurnal variation ${ }^{9}$, and diurnal variations exist in respiration $^{10)}$. The diurnal variation in respiration is known as the "morning dip" phenomenon, and evaluation of breathing at 4:00 pm gives the highest values, while the lowest values are measured in the morning ${ }^{11)}$. A review of previous studies of the diurnal variations of pulmonary evaluation suggests conflicting viewpoints. Hetzel ${ }^{12)}$ reported changes in pulmonary function and pulmonary strength with time, whereas Aguilar et al. ${ }^{13)}$ reported that pulmonary function and pulmonary strength showed no statistically significant changes with time. The purpose of this study was to identify the changes in pulmonary function and pulmonary strength associated with time of day.

\section{SUBJECTS AND METHODS}

The subjects were 20 healthy adults ( 11 men, 9 women) who had no cardiopulmonary-related diseases. The mean age, mean height, and mean weight of the subjects were $23.55 \pm 3.09$ years, $169.90 \pm 9.61 \mathrm{~cm}$ and $64.40 \pm 13.48 \mathrm{~kg}$, respectively. The subjects were explained the purpose of this 
study and they voluntarily signed informed consent forms before participation in this study. This study obtained the approval of the Bioethics Committee of Catholic University of Pusan (CUPIRB-2014-010).

The subjects' pulmonary function and pulmonary strength were evaluated at three times, 9:00 am, 1:00 pm, and 5:00 pm, based on the hospital's working environment. The tests were performed at least 1 hour after the subjects had eaten a meal. Pulmonary function was evaluated using MicroLAB (Micro Medical Ltd., UK). Each subject was seated and looked straight ahead with the mouthpiece of the measurement device inserted in the mouth and a nose clip fixed on the nose. The measurement items were FVC, FEV1, and $\mathrm{FEF}_{25-75 \%}$. Pulmonary strength was evaluated using MicroRPM (Micro Medical Ltd., UK) to measure MIP and MEP. The MIP and MEP were measured while the subjects were seated and looked straight ahead with the mouthpiece of the measurement device inserted in the mouth. Inhalation and exhalation were repeated three times, and the highest value was selected. If differences of more than $10 \%$ were found among the measured values, these values were excluded.

The data collected during the process were encoded and analyzed using SPSS for Windows ver. 20.0. The statistical significance level was chosen as $\alpha=0.05$. General characteristics of the subjects are shown as means and standard deviation. In addition, repeated measures analysis of variance (AVONA) was conducted to compare the differences in pulmonary function and pulmonary strength and contrast tests was used to compare between times of day.

\section{RESULTS}

The results of pulmonary function at the different times of day are shown in Table $1 . \mathrm{FEV}_{1}$ showed statistically significant differences among the different times of day. In addition, comparative testing of each variable revealed statistically significant differences. $\mathrm{FVC}$ and $\mathrm{FEF}_{25-75 \%}$ showed no statistically significant differences among the different times of day. The results of pulmonary strength at the different times of day are shown in Table 2. MIP and MEP showed no statistically significant differences among the different times of day, but comparative testing of each variable found statistically significant differences between measurements taken at 9:00 am and 5:00 pm.

\section{DISCUSSION}

Circadian rhythms are an autonomous biological survival response for adaptation to the environment ${ }^{14)}$. Diurnal variations are well-known in respiratory physiology. $\mathrm{Hu}$ man diurnal variations are controlled by the suprachiasmatic nucleus located in the anterior hypothalamus, which serves the role of the main circadian pacemaker that controls almost all human organs and behaviors ${ }^{15,16)}$. There are some studies of diurnal variations related to respiration. Bagg and Hughes ${ }^{11)}$ reported that diurnal variations exist in the peak expiratory flow (PEF): the highest value was observed at 4:00 pm and the lowest value was observed in the morning, the morning dip phenomenon. Teramoto et al. ${ }^{17)}$
Table 1. The changes of pulmonary function with time of day

\begin{tabular}{lccc}
\hline & $9: 00 \mathrm{am}$ & $1: 00 \mathrm{pm}$ & $5: 00 \mathrm{pm}$ \\
\hline $\mathrm{FVC}$ & $3.45 \pm 0.12^{\mathrm{a}}$ & $3.55 \pm 0.13^{\mathrm{a}}$ & $3.60 \pm 0.12^{\mathrm{a}}$ \\
$\mathrm{FEV}_{1}{ }^{*}$ & $3.15 \pm 0.10^{\mathrm{a}}$ & $3.35 \pm 0.10^{\mathrm{b}}$ & $3.45 \pm 0.09^{\mathrm{b}}$ \\
$\mathrm{FEF}_{25-75}$ & $4.40 \pm 0.22^{\mathrm{a}}$ & $4.50 \pm 0.19^{\mathrm{a}}$ & $4.45 \pm 0.18^{\mathrm{a}}$ \\
\hline
\end{tabular}

unit $=\ell$

*: Statistically significant $(\mathrm{p}<0.05)$

Different superscripts in a row indicate a significant difference.

Table 2. The changes of pulmonary strength with time of day

\begin{tabular}{lccc}
\hline & $9: 00 \mathrm{am}$ & $1: 00 \mathrm{pm}$ & $5: 00 \mathrm{pm}$ \\
\hline MIP & $72.0 \pm 4.3^{\mathrm{a}}$ & $73.4 \pm 3.9^{\mathrm{ab}}$ & $76.5 \pm 4.4^{\mathrm{b}}$ \\
MEP & $74.3 \pm 5.7^{\mathrm{a}}$ & $74.4 \pm 4.6^{\mathrm{a}}$ & $76.9 \pm 4.6^{\mathrm{a}}$ \\
\hline
\end{tabular}

unit $=\mathrm{cmH}_{2} \mathrm{O}$

Different superscripts in a row indicate a significant difference.

evaluated diurnal variations in $\mathrm{FVC}$ and $\mathrm{FEV}_{1}$. Their results displayed the morning dip phenomenon with significantly reduced values being observed in the morning. In the present study, the morning dip phenomenon could be observed. Teramoto et al. ${ }^{17)}$ reported their data as graphs. They did not tabulate the numerical values of their results, thereby limiting comparisons with our study. Medarov et al. ${ }^{18)}$ found that when $\mathrm{FVC}$ and $\mathrm{FEV}_{1}$ were values measured in the afternoon they showed were the highest values. The difference in FVC between the highest and the lowest values was $11.9 \%$, and the difference in $\mathrm{FEV}_{1}$ between the highest and the lowest values was $15.7 \%$. In the present study, FVC and $\mathrm{FEV}_{1}$ measured in the morning were about $4.2 \%$ and $8.7 \%$ less than their respective values measured in the afternoon. The $\mathrm{FEF}_{25-75 \%}$ measured in the morning was about $1.1 \%$ less than that measured in the afternoon, also displaying the morning dip phenomenon. Teramoto et al. ${ }^{17)}$ reported statistically significant diurnal variations in MIP and MEP, but, as mentioned above, they did not tabulate the numerical values of their results, thereby limiting comparisons with our study. Fregonezi et al. ${ }^{19)}$ measured the diurnal variations of 7 COPD patients. The MIP and MEP values in the morning were a little higher than those measured in the afternoon. While their study reported statistically significant differences, the small subject number limits its generalizability. Aguilar et al. ${ }^{13)}$ measured the diurnal variations of MIP and MEP of healthy adults for 12 hours. MIP decreased about $4.6 \%$, MEP increased around $1.3 \%$ during the day, and MEP exhibited the morning dip phenomenon. In the present study, MIP and MEP measured in the morning were respectively about $5.9 \%$ and $3.3 \%$ less than the MIP and MEP measured in the afternoon. Thus, they demonstrated the morning dip phenomenon, but the differences were not statistically significant.

The results of the present study demonstrate that pulmonary function and pulmonary strength show changes with time of day, confirming the morning dip phenomenon, 
though the differences were small. Although the differences were small, the morning dip phenomenon appeared throughout the experiment, sometimes showing statistically significant difference. Therefore, we consider the time of measurement is a matter of clinical concern. This study was performed with healthy Asian adults in their 20s as subjects; therefore, the results cannot be generalized to the elderly or patients with lung disorders. Some studies have reported that pulmonary evaluation measurements are influenced by gender, ethnicity, age, and height, and thus these factors should be taken into account in testing ${ }^{5,20)}$. Follow-up studies should be conducted considering other factors, such as the age and disease of patients.

\section{REFERENCES}

1) Muirhead R, Featherstone C, Duffton A, et al: The limited clinical benefit of respiration gated radiotherapy (RGRT) in non-small cell lung cancer (NSCLC). Lung Cancer, 2010, 67: S30-S31. [CrossRef]

2) KOSTAT: Cause of death statistics. Korean Statistical Information Service, 2012

3) Sutbeyaz ST, Koseoglu F, Inan L, et al.: Respiratory muscle training improves cardiopulmonary function and exercise tolerance in subjects with subacute stroke: a randomized controlled trial. Clin Rehabil, 2010, 24: 240-250. [Medline] [CrossRef]

4) Frownfelter DL, Dean E: Cardiovascular and pulmonary physical therapy Elsevier Mosby, 2006.

5) Cherniack RM: Evaluation of respiratory function in health and disease. Dis Mon, 1992, 38: 505-576. [Medline] [CrossRef]

6) Kerstjens HA, Rijcken B, Schouten JP, et al.: Decline of FEV1 by age and smoking status: facts, figures, and fallacies. Thorax, 1997, 52: 820-827. [Medline] [CrossRef]
7) Ma LL, Kong DG, Qi XW, et al.: Generalized anxiety disorder and the circadian rhythm of blood pressure in patients with hypertension. Int J Psychiatry Clin Pract, 2008, 12: 292-295. [Medline] [CrossRef]

8) Mittal SR: Diurnal variations in blood pressure: importance of ambulatory BP monitoring. J Assoc Physicians India, 2013, 61: 410-411. [Medline]

9) Kwon YH, Choi YW, Nam SH, et al.: The influence of time of day on static and dynamic postural control in normal adults. J Phys Ther Sci, 2014, 26: 409-412. [Medline] [CrossRef]

10) Cardone L, Hirayama J, Giordano F, et al.: Circadian clock control by SUMOylation of BMAL1. Science, 2005, 309: 1390-1394. [Medline] [CrossRef]

11) Bagg LR, Hughes DT: Diurnal variation in peak expiratory flow in asthmatics. Eur J Respir Dis, 1980, 61: 298-302. [Medline]

12) Hetzel MR: The pulmonary clock. Thorax, 1981, 36: 481-486. [Medline] [CrossRef]

13) Aguilar X, Fiz JA, Texidó A, et al.: Maximum inspiratory and expiratory pressures have no daytime variation in healthy men. Respir Med, 1996, 90: 231-233. [Medline] [CrossRef]

14) Durrington HJ, Farrow SN, Loudon AS, et al.: The circadian clock and asthma. Thorax, 2014, 69: 90-92. [Medline] [CrossRef]

15) Gibbs JE, Beesley S, Plumb J, et al.: Circadian timing in the lung; a specific role for bronchiolar epithelial cells. Endocrinology, 2009, 150: 268-276. [Medline] [CrossRef

16) Reppert SM, Weaver DR: Molecular analysis of mammalian circadian rhythms. Annu Rev Physiol, 2001, 63: 647-676. [Medline] [CrossRef]

17) Teramoto S, Suzuki M, Matsui H, et al.: Influence of age on diurnal variability in measurements of spirometric indices and respiratory pressures. J Asthma, 1999, 36: 487-492. [Medline] [CrossRef]

18) Medarov BI, Pavlov VA, Rossoff L: Diurnal variations in human pulmonary function. Int J Clin Exp Med, 2008, 1: 267-273. [Medline]

19) Fregonezi G, Resqueti VR, Cury JL, et al.: Diurnal variations in the parameters of pulmonary function and respiratory muscle strength in patients with COPD. J Bras Pneumol, 2012, 38: 257-263. [Medline] [CrossRef]

20) Alghadir A, Aly F, Zafar H: Sex-based differences in lung functions of Saudi adults. J Phys Ther Sci, 2012, 24: 5-9. [CrossRef] 